\title{
PAPER AND PENCIL RESEARCH IN THE COLLEGE CLASSROOM
}

\author{
By Donald A. LaIrd, University of Iowa
}

It was about two decades ago that psychology extended its methods to include more than the prosaic brass instrument laboratory and philosophic convictions. It was about this long ago that the paper and pencil psychologist ushered in the era of tests. Paper and pencil methods were employed in psychological work early in its development. Questionnaires were used to a large extent by the early student of the psychology of religion and during the epoch of child study. The test method, properly termed, however, as it has been developed and brought nearer to perfection by the modern paper and pencil psychologist is of much more recent origin and is rapidly becoming a science unto itself.

More recently the staid study of education has turned to the test methods for a solution of many practical problems in educational procedure in an experimental manner. Still more recently sociology has adopted this method to its subject matter and much is to be expected from its application in this field.

The Great War precipitated the paper and pencil psychologist into a popularity and an esteem scarcely anticipated by the most enthusiastic advocate. In the period of reconstruction a deluge of tests has appeared, well nigh swamping the worker and the student in the onslaught of tests of this and that. The progress of educational tests has been less stimulated by the war impetus. Their development has been more gradual and perhaps more normal but still they are receiving increasing and just recognition and are being turned out in increasing numbers. Truly we are well into the test era.

It is not my purpose in this brief paper to cast a critical eye upon paper and pencil psychology, education, and sociology. Measured in terms of practical results much can be said for them. Viewed from other angles their hues are not nearly so roseate. For the present I must confine my remarks to another aspect of the test method which seems to be largely overlooked.

Under the urge to devise new tests and assist in the standardization of recent tests it has become the quite common 
practice for the instructor to use his students not alone for contributing data but to lend a hand in the scoring and tabulating of the results. The pedagogical value of such procedure is at least nebulous if not positively doubtful. Certain it is that those who contribute the data receive negative returns. Especially is this true when, through the kindness of fellow teachers in other departments, a test which pertains not at all to the work at hand is given for the avowed purpose of obtaining data sufficient for the establishment of norms. Such instances' are not of infrequent occurrence. Due to the large number of datum necessary for adequate statistical treatment this undesirable aspect becomes much magnified.

Those students who assist in the tabulation and the statistical treatment of the data probably receive some experience which is of slight educational value but whether or not this justifies the exploitation of the masses is an open question which it would seem should be decided in favor of the masses. The principal value attaching to the tabulation and treatment of data by the student is in training for research. Even this can be debated for plainly routine testing is not research nor is it especially conducive to a research attitude. As for the underclassmen-they are simply Versuchtiere.

Faculty committees are very prone to discuss ways and means for securing a better use of time by the students. To promote strict class attendance it is decreed that more than three absences from any course will cut into the credits received. Midweek parties are prohibited that the time of the students may not be utilized too largely in extra-curricular activities. It might be well for some of these committees to reflect likewise upon the instructors' opportunities for securing a better use of the students' time in the class room.

Now my thesis-one must always have a thesis nowadays -is that in a rather considerable and rapidly increasing number of instances much of the college and normal school students' time in the classroom is exploited by their teachers in paper and pencil research with but meagre, if any, returns to the student himself. As a judgment of value it would seem that if the students' time and efforts are to be utilized in the classroom it should be in a manner that will bring the students at least some momentary satisfaction if not something of permanent educational value.

I do not think I am making a mountain out of a mole hill. Anyone who has had an opportunity to observe the more recent progress and popularization of the test method cannot have failed to note that this is a factor which is assuming 
a large magnitude in proportion to the pedagogical value which attaches to it in classroom routine. Almost innumerable examples could be given of this exploitation of classroom time within a single institution but for reasons which are on the surface it is perhaps best not to be too definite in the present communication. There is also probably little need of dragging in a large array of statistics for every college teacher is or should be aware of the situation which I have brought up for consideration. One who is given to playing with figures might treat this topic with results that would make the infant mortality charts furious with envy.

Probably no one will take offense if I use myself as my " horrible example." I have been guilty of using class timelots of it-for paper and pencil research in gathering material which had not the remotest connection with their class work. I admit it blandly and complacently for I feel it has the stamp of social approval. The material I obtained, however, turned out to be extremely barren so now we refer to it as preliminary material. (Those who have been reading too much psychoanalysis please note.) To obtain this material three hundred students were detained from more worthwhile class work for a period of fifty minutes. The total time which I thus exploited was fifteen thousand minutes or two hundred and fifty hours. Thus through the willingness of two instructors and the dean of a college who aided and abetted me I consumed more than the equivalent of the time one student would have spent in class work during that quarter. ${ }^{1}$

But my experience is by no means typical. If this prelimunary material had warranted more thorough work I would probably not have stopped short of a thousand cases. I also would have used other and more advanced classes for the marking, tabulating, and correlating. Which, again translated into terms of the average students' classroom schedule would mean an entire year's work!

A great deal has been accomplished in a practical way with the use of tests and their development should undoubtedly be furthered. Whether or not the college and university is the proper place for such development, however, is another question and one which I feel should be answered in the negative. The functions of a college or a university are instruction, furthering the sum total of human knowledge, and furthering its own interests. Let us take these up in the reverse order.

1 It is just that I state that this is not the school from which I am writing. 
One of the means by which an educational institution may further its own interests is to encourage its staff to contribute from time to time to the sum total of human knowledge. Thus in some respects the last two functions can be combined in one work. With the advent of paper and pencil research mirabile dictu it seemed as if by a sudden stroke of providence it would be possible to combine all these functions and fuse them together. Superficially this may be true. The first and all important function of an institution of higher learning, to which all other functions should be contributory, is instruction. And teaching is something far more than using classroom time. It is obvious that the development of tests-educational, psychological, sociological, and what notin the class period is neither instruction nor education for the average run of underclassmen. The development of such methods and materials in the class room should be discouraged except, perhaps, in special classes organızed solely for that purpose.

\section{COMMUNICATIONS AND NOTES}

\section{A NEW LABORATORY IN CHILD PSYCHOLOGY}

The Iowa Child Welfare Research Station at the State University has organized a Laboratory in Child Psychology for experimental work with children from 2 to 4 years of age A new four-roomed building has been constructed and 24 children are now in attendance daily, in two sections from 9 to 12 o'clock. The laboratory is under the immediate direction of Dr Bird T. Baldwin, Research Professor in Psychology, and Dr Lorle I. Stecher, Research Assistant Professor, with graduate student assistants.

Oct. 12, 1921

B. T BALDWIN 